\title{
Power Quality Detection, Classification and Monitoring Using LABVIEW
}

\author{
Fatma Zohra DEKHANDJI, Salim TALHAOUI and Youcef ARKAB \\ Smart Grid Team, Laboratory of Signals and Systems, Institute of Electrical and Electronic \\ Engineering, University M'hamed Bougara of Boumerdes \\ Boulevard de l'indépendance, 35000, Boumerdes, Algeria \\ fzdekhandji@univ-boumerdes.dz
}

\begin{abstract}
In recent years, Power Quality becomes increasingly a major concern for both electric utilities and end users. Accordingly, the electrical engineering community has to deal with the analysis, diagnosis and solution of $P Q$ issues using system approach rather than handling these issues as individual problems. This paper describes the analysis of $P Q$ using advanced signal processing tools represented in Hilbert \& Wavelet Transforms (HT-WT) and artificial intelligence tools represented in Artificial Neural Network \& Support Vector Machine (ANN-SVM) for detection and classification of power quality disturbances respectively. These techniques were successfully simulated using LABVIEW software capabilities. The results of simulation indicate that the signal processing techniques are effective mechanisms to detect and classify power quality disturbances. At the end, the combination of WT as a tool of detection and features extraction with SVM as a classifier tool resulted as the best combination for $\mathrm{PQ}$ monitoring system.
\end{abstract}

Keywords: Power quality, detection, classification, monitoring, LABVIEW

\section{INTRODUCTION}

Power quality is known as one of the very serious issues in electric power transmission and distribution, manufacturers and end users because of its awful effects on electricity suppliers [1]. Power quality is a term of many meanings; each meaning relies on the reference to which it is attributed. For example, a utility may define power quality as reliability of its system. A manufacturer of load equipment may define power quality as those features of the power supply that enable the equipment to work properly. The end user's point of view of power quality is that any power problem manifested in voltage, current, or frequency deviations that result in failure or malfunction of customer equipment [2]. Power quality is generally meant to express the quality of voltage and/or the quality of current which can be defined as: the measure, analysis, and improvement of the bus voltage to maintain a sinusoidal waveform at rated voltage and frequency; this definition includes all momentary and steady-state phenomena [3].

Cite this article as:

Fatma Zohra DEKHANDJI, Salim TALHAOUI and Youcef ARKAB, "Power Quality Detection, Classification and Monitoring Using LABVIEW", Algerian Journal of Signals and Systems, Vol. 4, Issue 2, December 2019. pp: 101-111.
All electrical devices are likely to fail or not work properly when exposed to one or more power quality problems; these devices react negatively to power quality issues, depending on the severity of problems. A simpler and a more concise definition states: "Power quality is a set of electrical boundaries that allows a piece of equipment to function in its intended manner without significant loss of performance or life expectancy." This definition contains things needed from electrical devices which are performance and life expectancy [4]. It is common experience that electric power of poor quality has harmful effects on different equipment and systems. More than that, power system stability, continuity and reliability fall with the degradation of quality of electric power [5].

There are four main reasons for engineers to increase concern about the need for energy quality [2]:

1. Newer-generation load equipment, with microprocessor-based controls and power electronic devices, are more sensitive to power quality variations than was equipment used in the past.

2. The increasing focus on overall power system efficiency has resulted in continued growth in the use of devices such as highfrequency, adjustable-speed motor drives and shunt capacitors for power factor correction to reduce losses. This is resulting 
in increasing harmonic levels on power systems and has many people worried about the future effect on system abilities.

3. End users have an increased knowledge of power quality issues. Utility customers are becoming better informed about such issues as interruptions, sags, and switching transients and are challenging the utilities to improve the quality of power delivered.

4. Many things are now interconnected in a network. Integrated processes mean that the failure of any part has much more important results. The common thread running through all these reasons for increased concern about the quality of electric power is the continued push for increasing productivity for all utility customers. Manufacturers want faster, more productive, more efficient machinery. Utilities encourage this effort because it helps their customers become more beneficial and also helps put off large investments in substations and generation by using more efficient load equipment. Interestingly, the equipment installed to increase the productivity is also often the equipment that suffers the most from common power disturbances. And the equipment is sometimes the source of adding more power quality problems. When whole processes are automated, the efficient operation of machines and their controls becomes more and more dependent on quality power [2].

The power system faces many issues; some of them shut it down causing a blackout of the network, the main problems that can cause harm to the power system are: Voltage sag or dip; Very short interruptions; Long interruptions; Voltage spike; Transients; Voltages swell; Harmonic distortion; Voltage fluctuation; Noise and Voltage unbalance. Power quality disturbances have become a serious issue in power world, and this is because of the great damage that they caused to the system from the generation to the end users. For this reasons a power quality monitoring system must be included in the electrical network in order to: detect, classify and mitigate these problems. Many researchers have focused their attention on this goal, on how to create a monitoring system capable of detecting the disturbances the moment they appear and then classify them according to their parameters [6]. Detection techniques are numerous, each one distinct from the others; but the fastness time response to detect the disturbance is the major concern of all the studies. Classification is also an important step in the monitoring, after the system detects a disturbance it must be recognized [6]. The objective of the classifier is to identify the events and must have a perfect percentage of accuracy and precision.

\section{THEORITICAL BACKGROUND}

The important issues in power quality (PQ) problems are to detect and classify disturbance waveforms automatically in an efficient manner [7]. In order to improve electric power quality, the sources and causes of disturbances must be known before appropriate mitigating action can be taken, and continuous recording of disturbance waveforms is necessary [8]. Therefore, the monitoring equipment needs to firstly and accurately detect and identify the disturbance types. Thus, the uses of new and powerful tools of signal analysis have enabled the development of additional methods to accurately characterize and identify several kinds of power quality disturbances [9]. Therefore, two methods of both detection and classification are introduced and used for power quality monitoring.

\section{A. Detection methods}

Detection methods are designed to identify the occurrences of disturbances. An effective method of detecting power quality events such as (sag, swell, harmonics, interruption, flicker and transient) is dependent on their accurate measurements in time which is still a challenge for researchers and engineers [10]. Signal processing techniques are widely used in analyzing $P Q$ events to extract the most sensitive and interesting features concerning disturbances, these techniques are classified as using time domain, frequency domain, and time-frequency domain methods [11-12]. Some examples are the fast Fourier Transform method, Fractal-Based method, STransform method (ST), Time- Frequency Ambiguity Plane method, Short Time Power and Correlation Transform method, Chirp-Z Transform (CZT), Wavelet Transform (WT) method, and Hilbert Transform (HT) [12], these two later have been proven to be effective signal processing tools for the detection and analysis of power signals.

\section{a- WaveletTransform}

The Wavelet Transform (WT) has been found to be particularly useful for analyzing signal which is mostly non-stationary and can be best described as aperiodic, noisy, intermittent, transient and so on. Therefore, it represents one of the powerful signal 
processing algorithms that is used in the field [13]. It has the ability to analyze different power quality problems simultaneously in both time and frequency domains in a distinctly different way from the traditional tools such as Fourier Transform [7] [12], and this is why it overcomes the resolution limitation of FT. The main advantage of wavelets is that they have a varying window size, which is wide for slow frequencies and narrow for fast, thus leading to an optimal time frequency resolution in all frequency ranges [14].WT has two categories primarily called Continuous Wavelet Transform (CWT) and Discrete Wavelet Transform (DWT) [15].

b- Multi Resolution Analysis(MRA)

The wavelet Multi-Resolution Analysis is a tool that utilizes DWT for the analysis of waveforms and images. In power quality, MRA can be used for detection as well as for distortion features extraction. The goal of MRA is to develop representations of a signal at various levels of resolution by decomposing the time domain signal [11] [16]. Wavelet functions and scaling functions are used as building blocks to decompose and reconstruct the signal at different resolutions in MRA [17].

\section{c- $\quad$ The Hilbert Transform}

The Hilbert Transform (HT) has been used widely in the telecommunication research for signal modulation and demodulation, and in various medical image processing applications. In power quality signal analysis, the HT has not been investigated, although it shows an accurate tracking of the changes in the power quality signals.

\section{B. Classification methods}

The main task of power quality (PQ) disturbance recognition is to accurately identify the disturbance type, and provide the references for parameter estimation and control strategies of power system [18]. Therefore continuous monitoring and classification are required for these disturbances due to increasing demand of pure power [19]. To perform the classification of these disturbances different algorithms have been defined in order to relate the signal characteristics with the group they belong to: Decision Trees (DTs), Fuzzy Logic (FL), Neural Networks (NNs), and Support Vector Machine (SVM), among others. These methodologies play an important role on the disturbance classification because their performance depends on the extracted features and the classifier utilized; if the disturbance characteristics are not accurately captured, the performance is also limited[20].

\section{a- Artificial neural network}

Artificial Neural Networks have been developed as generalizations of mathematical models of human cognition or neural biology. A neural network is characterized by [21]:

- Its pattern of connections between the neurons (called architecture).

- Its method of determining the weights on the connections (called training or learning algorithm).

- Its activation function.

All definitions of Artificial Neural Networks emphasize the idea of highly interconnected units comprising simple nonlinear elements [22]. Neural Networks have been extensively used for the classification because of their large data handling capability. They are used to recognize and classify complex fault patterns without much knowledge about the system they deal with. The neural networks are described by the transfer function of their neurons, by training algorithm and by the connecting formula [23]. Artificial Neural Networks (ANNs) have attracted a great deal of attention because of their pattern recognition capabilities, and their ability to handle noisy data; however, its ability to perform well is greatly influenced by the weight adaptation algorithm and the amount of noise in the data [24].

\section{b- Support Vector Machine}

The Support Vector Machine (SVM) is one of the most prominent techniques in supervised machine learning that have attracted a significant amount of attention in the field of machine learning over the past decade by proving themselves to be very effective in a variety of real-world pattern classification and regression estimation tasks [25]. It has been applied to the problems of dependency estimation, forecasting, and constructing intelligent machines [26]. SVM is a statistical learning technique based on structural risk minimization method. Its main objective is building a model with the use of training set, where each sample belongs into one of the two possible classes, class 1 or class 2 . With the trained SVM, a prediction model can be achieved [27], which can deal with linear and nonlinearly separable models using a hyperplane based on theoretical results from the statistical learning theory [28]. SVM classification typically involves two classes. For applications that involve more than two classes, multi-class SVM classifiers are obtained by combining two-class SVMs. The SVM algorithm uses two approaches [29]: 
- One-versus-all approach: it is the most fundamental approach and it utilizes $(P-1)$ classification models (with $P$ is the number of classes). Each machine is trained as a classifier of one class against all other classes.

- One-versus-one approach: in this approach, $(P \times(P-1) / 2)$ classification models so that each machine is trained as a classifier for one class against other class. In order to evaluate the classifier, pair wise competition between all the machines is performed; each winner competes against another winner until a single winner remains. This final winner determines the class of the test data.

\section{SIMULATION RESULTS AND DISCUSSIONS}

Simulation studies have been performed to investigate the performance of the power quality detection and classification methods. In this section, the description of the methods shown in the block diagram, simulated circuits and their results are discussed including the fastness (time response) of the detection methods and the precision of the classification ones. Two methods for detection and four combinations for classification were simulated.

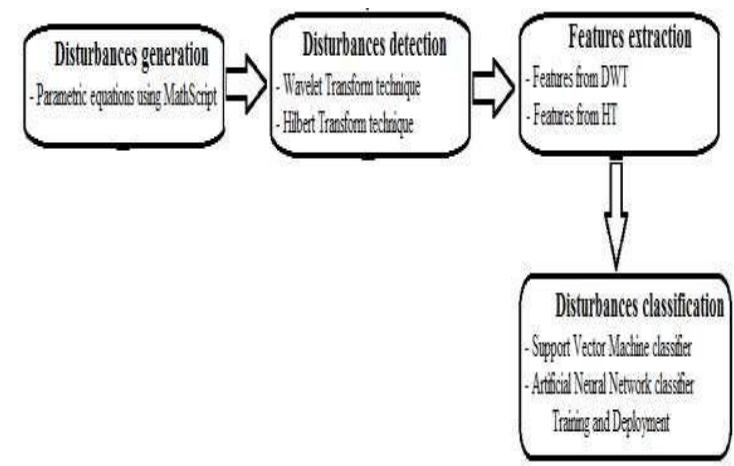

Fig. 1 Block diagram of PQDs detection \& classification

The software used for the simulation is the National Instruments Laboratory Virtual Instrument Engineering Workbench (LABVIEW). It is a development environment based on the graphical programming language G. LABVIEW programs are called Virtual Instruments, or VIs. A VI contains the three components: the front panel, the block diagram, and the icon and connector panel; The front panel serves as the user interface whereas the block diagram contains the graphical source code that defines the functionality of the VI, The icon and connector pane identifies the VI so that a VI can be used in another $\mathrm{VI}$ [30].

The work starts with the generation of power quality events using the parametric equations represented in Table (1). In addition to a pure sine wave with amplitude of $230 \mathrm{~V}$ and frequency of $50 \mathrm{~Hz}$, eight types of PQDs that commonly occur in power systems were generated including sag, swell, interruption, harmonics, transient, flicker, sag with harmonics, and swell with harmonics. The different parameters of signals represented in the starting time, duration and distortion magnitude were generated randomly.

Table 1 Signal Modeling of Power Quality Events

\begin{tabular}{|c|c|c|}
\hline PQES & Model Equations & Parameters \\
\hline Sine & $(t)=A \sin (\omega t)$ & $\begin{array}{c}A=230 \\
f=50 \mathrm{~Hz}\end{array}$ \\
\hline Sag & $\begin{array}{c}(t)=(1-((t-t 1)-(t-t 2))) \\
\sin (\omega t)\end{array}$ & $\begin{array}{c}0.1 \leq \alpha \leq 0.9 \\
\mathrm{~T} \leq \mathrm{t} 2-\mathrm{t} 1 \leq 9 \mathrm{~T}\end{array}$ \\
\hline Swell & $\begin{array}{c}(t)=A(1+\alpha(u(t-t 1)- \\
u(t-t 2))) \sin (\omega t)\end{array}$ & $\begin{array}{l}0.1 \leq \alpha \leq 0.8 \\
\mathrm{~T} \leq \mathrm{t} 2-\mathrm{t} 1 \leq 9 \mathrm{~T}\end{array}$ \\
\hline Interruption & $\begin{array}{c}(t)=(1-((t-t 1)-(t-t 2))) \\
\sin (\omega t)\end{array}$ & $\begin{array}{c}0.9 \leq \alpha \leq 1 \\
\mathrm{~T} \leq \mathrm{t} 2-\mathrm{t} 1 \leq 9 \mathrm{~T}\end{array}$ \\
\hline Harmonics & $\begin{array}{c}(t)=[\sin (\omega t)+\alpha 3 \sin (3 \omega t) \\
+\alpha 5 \sin (5 \omega t)+\alpha 7 \sin (7 \omega t) \\
]\end{array}$ & $\begin{array}{c}0.05 \leq \alpha 3 \leq \\
0.15 \\
0.05 \leq \alpha 5 \leq \\
0.15 \\
0.05 \leq \alpha 7 \leq \\
0.15\end{array}$ \\
\hline Transient & $\begin{array}{c}f(t)=A[\sin (\omega t)+\alpha \exp (-(t- \\
t 1) / \tau)] \sin (\omega \operatorname{tr}(t- \\
t 1))\end{array}$ & $\begin{array}{c}\tau=0.008-- \\
0.04 \mathrm{sec} \\
\omega \operatorname{tr}=100-- \\
400 \mathrm{~Hz} \\
0.1 \leq \alpha \leq 0.9\end{array}$ \\
\hline Flicker & $\begin{array}{c}(t)=A \sin (\omega t)(1+ \\
\beta \sin (\gamma \omega t))\end{array}$ & $\begin{array}{l}0.1 \leq \beta \leq 0.2 \\
0.1 \leq \gamma \leq 0.2\end{array}$ \\
\hline $\begin{array}{c}\text { Sag \& } \\
\text { harmonics }\end{array}$ & $\begin{array}{c}f(t)=A[1-\alpha(u(t-t 1)- \\
u(t-t 2))][\sin (\omega t)+\alpha 3 \\
\sin (3 \omega t)+\alpha 5 \sin (5 \omega t)+\alpha 7 \\
\sin (7 \omega t)]\end{array}$ & $\begin{array}{c}0.1 \leq \alpha \leq 0.9 \\
0.05 \leq \alpha 3 \leq \\
0.15 \\
0.05 \leq \alpha 5 \leq \\
0.15 \\
0.05 \leq \alpha 7 \leq \\
0.15\end{array}$ \\
\hline $\begin{array}{l}\text { Swell \& } \\
\text { harmonics }\end{array}$ & $\begin{array}{c}f(t)=A[1+\alpha(u(t-t 1)- \\
u(t-t 2))][\sin (\omega t)+\alpha 3 \\
\sin (3 \omega t)+\alpha 5 \sin (5 \omega t)+\alpha 7 \\
\sin (7 \omega t)]\end{array}$ & $\begin{array}{c}0.1 \leq \alpha \leq 0.8 \\
0.05 \leq \alpha 3 \leq \\
0.15 \\
0.05 \leq \alpha 5 \leq \\
0.15 \\
0.05 \leq \alpha 7 \leq \\
0.15\end{array}$ \\
\hline
\end{tabular}

\section{A. Detection methods}

The event detection is performed via Discrete Wavelet Transform VI and Fast Hilbert Transform VI for the DWT and HT's detection methods, respectively. For DWT, the mother wavelet chosen is fourth-order Daubechies (db4) and the MRA is of 5 levels. The detection is made using the third level 
detailed coefficient signal (D3). The simulated circuit is shown in Figure (2) below.
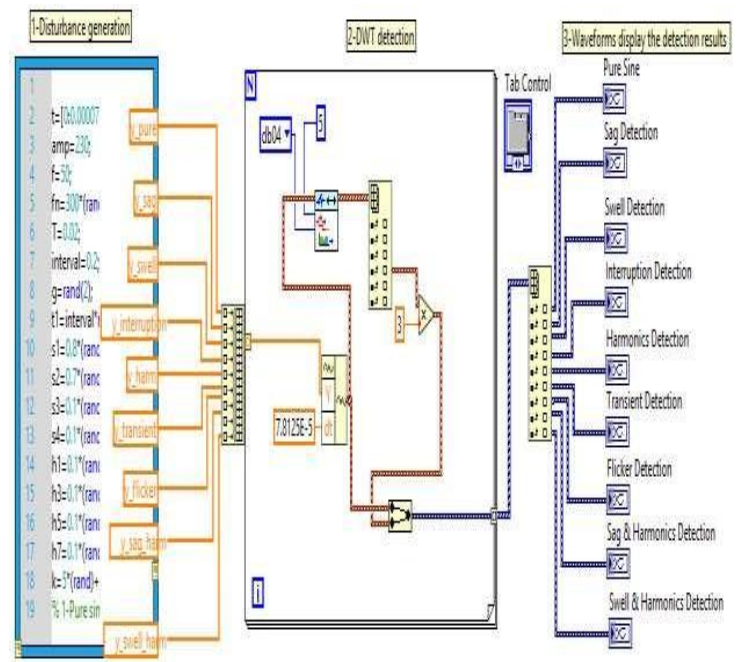

Fig. 2 Detection circtuit of the DWT

The results of detection are shown in the Figure (3).

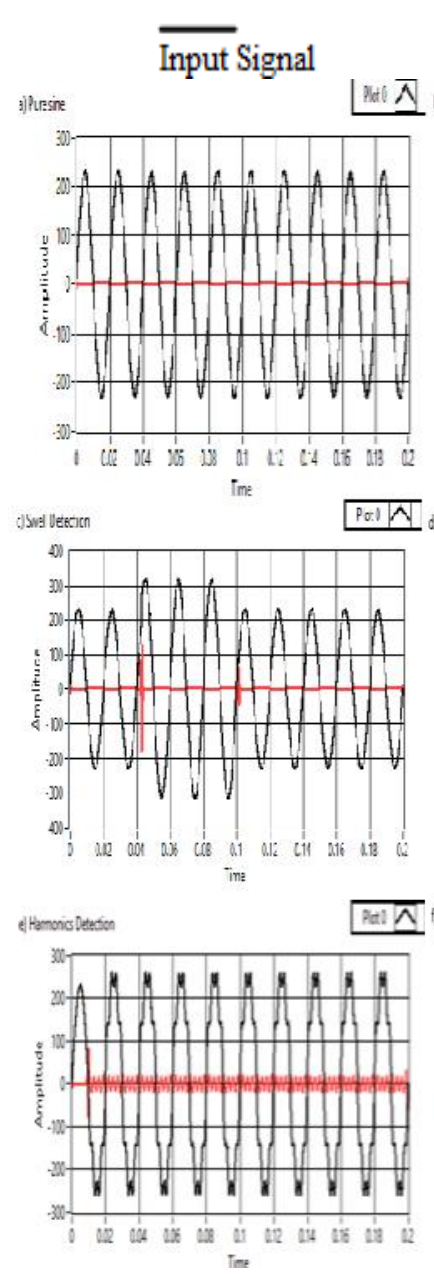

WT Detection $P_{t \in]} \overline{\mathrm{A}}$
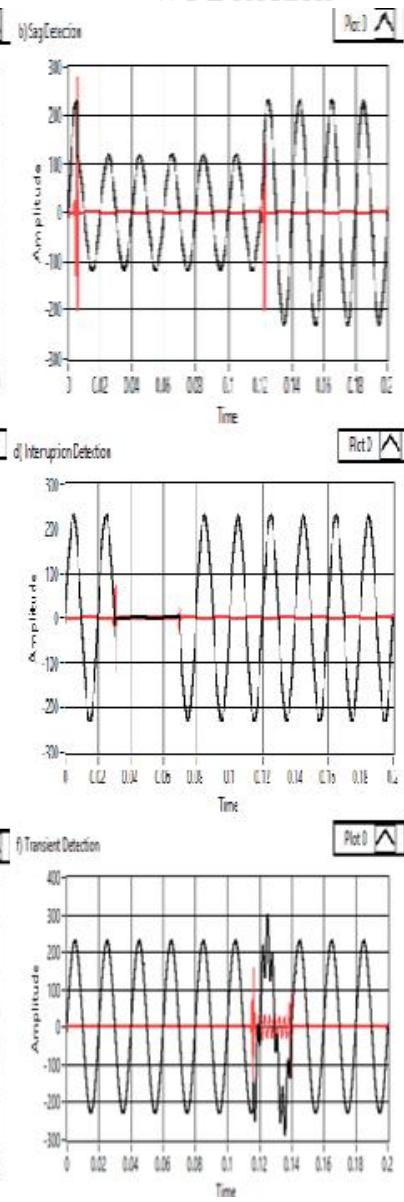

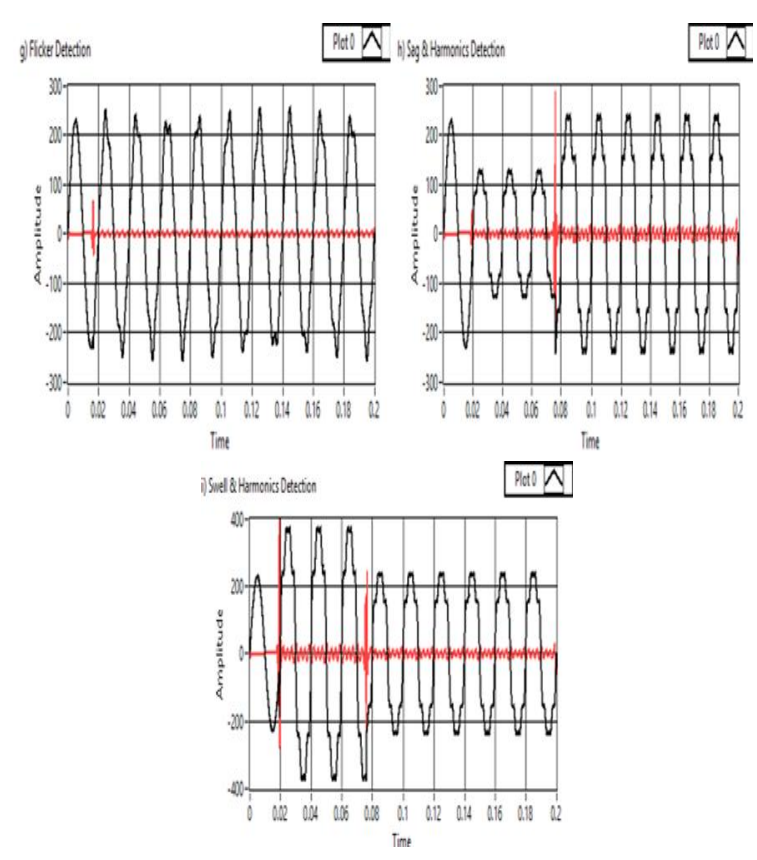

Fig. 3 Detection results using DWT

For the HT, the phase shifting algorithm has been applied to the different disturbances using the envelope of the transform as shown in Figure (4).

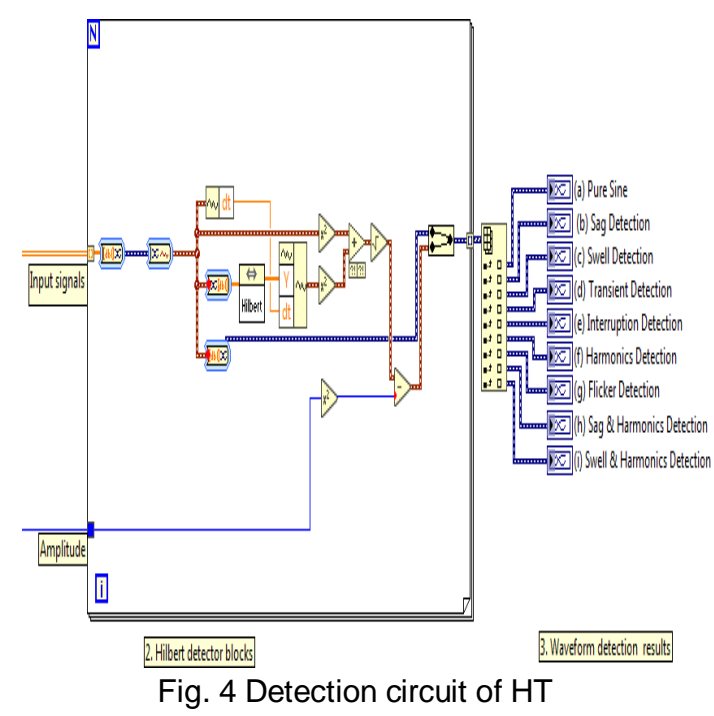

The disturbances have been successfully detected the results are illustrated in Figure (5).

As it is mentioned in Figures 4 and 5, the two proposed methods detected the eight disturbances successfully and for the pure sine signal the detector signals stayed a straight line along the $x$-axis to indicate the absence of any disturbance. 


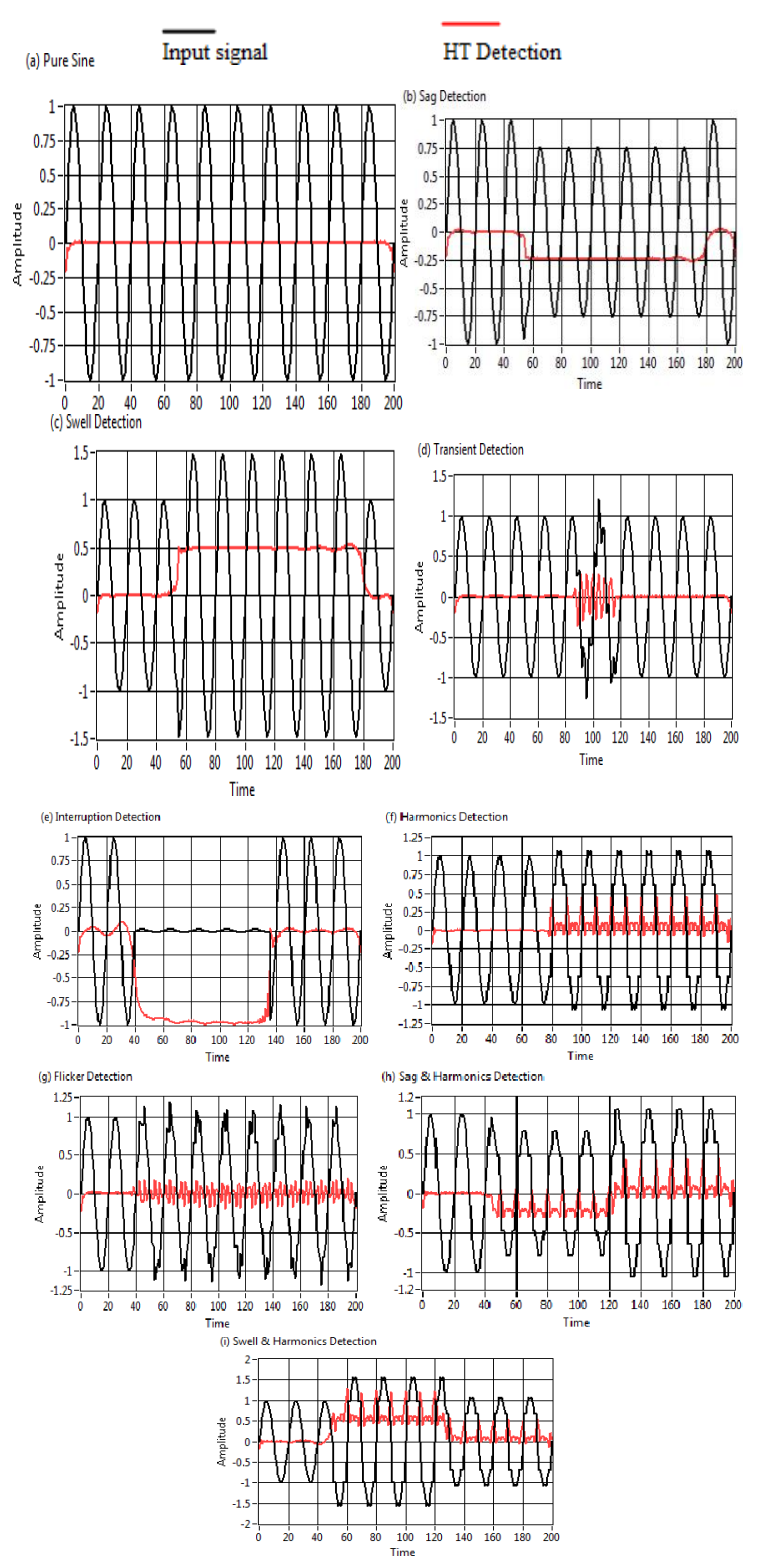

Fig. 5 Detection results of HT

- For DWT method, the detection is made by spikes at the starting and ending time of disturbance. Therefore in addition to detect the disturbance, it measures the period of disturbance occurrence and that is an advantage for it.

- For HT method, the detection is made by reshaping the envelope according to the shape of disturbance depending on its magnitude. Therefore the advantage of this method is giving information about the amplitude of disturbance.

- For the detection of starting time, the Wavelet detection has a higher time response than the Hilbert detection which has also an acceptable time response. This is due to the spikes generated by DWT.

\section{B. Features extraction}

Before the classification stage takes place, a stage of feature extraction stage must be done. The input of the classifier is a preprocessed signal generated from this stage. Feature extraction is the key for pattern recognition so that it is the most important component of designing the intelligent system based on pattern recognition since even the best classifier will perform poorly if the features are not chosen well. In this work, the preprocessed signal was generated using features of DWT and HT once a time.

For the WT, the wavelet coefficients obtained from discrete wavelet and multiresolution analysis of the disturbance signal represented in $1^{\text {st }}$ level detailed coefficient (D1), $5^{\text {th }}$ level detailed coefficient (D5), and $5^{\text {th }}$ level approximated coefficient (A5) were used for the construction of feature vector by calculating the three features based on DWT for each coefficient. Figure (6) represents the block diagram for the feature extraction.

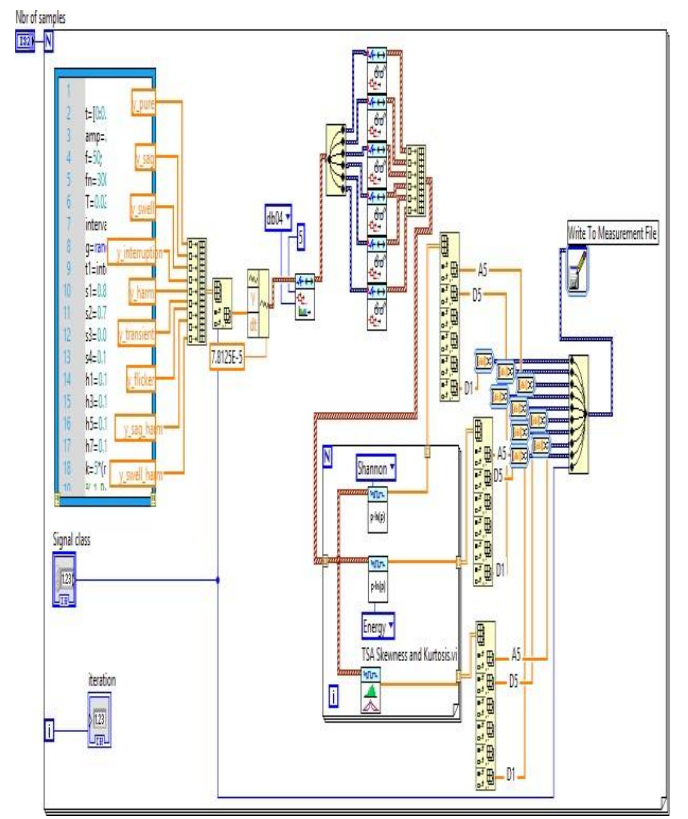

Fig. 6 Feature extraction circuit based on DWT

\section{Classification methods}

After preparing two different training data, they were utilized as the inputs of the untrained models SVM and ANN. These two late are available blocks in LABVIEW. Four proposed methods resulted from the possible combination between training data and classifiers. The methods are: 
- Training data obtained from DWT as trained data for SVM classifier denoted as DWT-SVM.

- Training data obtained from HT as trained data for SVM classifier denoted as HT-SVM.

- Training data obtained from HT as trained data for ANN classifier denoted as HT-ANN.

- Training data obtained from DWT as trained data for ANN classifier denoted as DWT-ANN.

The training process of the two classifiers is shown in the next two Figures (8) and (9), where the test data file in the figures is the CSV file contains the training data obtained from the features extraction.

\section{a- SVM Classifier:}

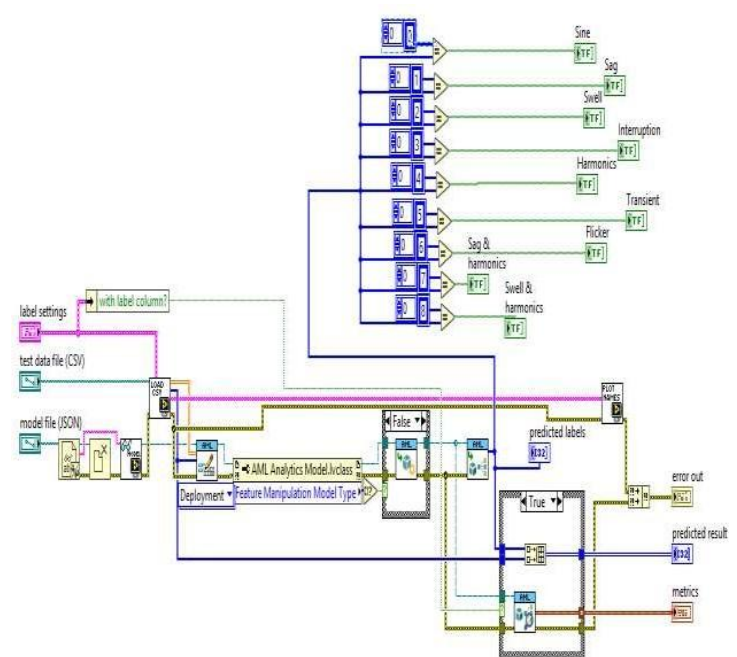

Fig. 8 Testing circuit of SVM classifier

b- ANN classifier:

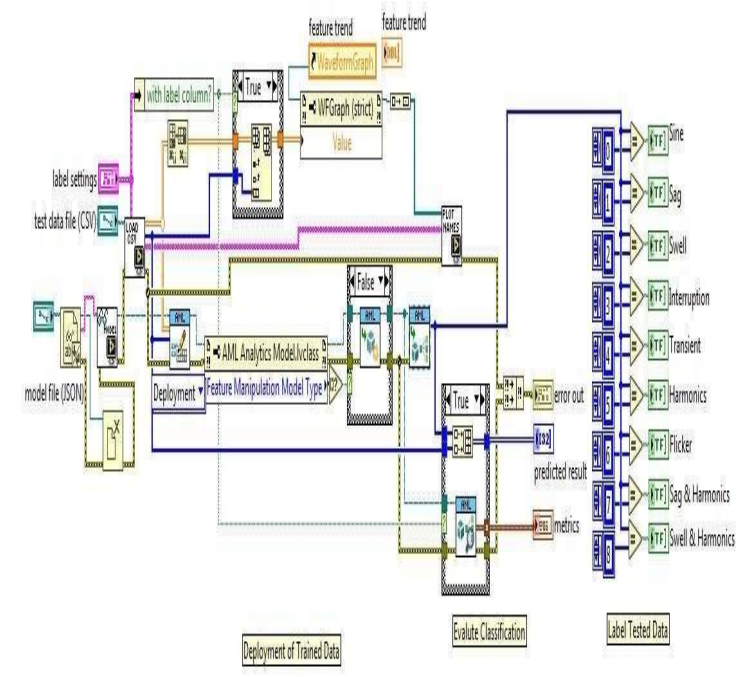

Fig. 9 Testing circuit of ANN classifier
The classification model parameters were set automatically by the model itself using cross validation techniques as shown in Figure (10).

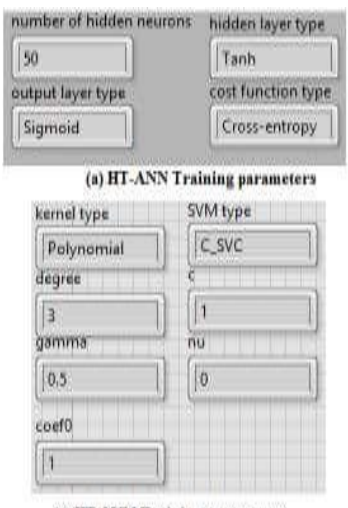

(c) HT. SVM Training parameters

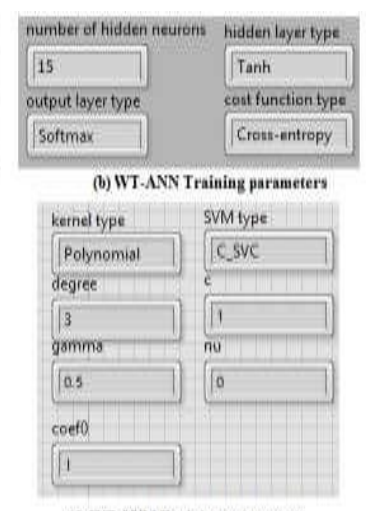

(d) WT-SVM Training parametern
Fig. 10 Parameters of training Classifiers

100 testing data sample for each class were used to test the performance of each method. The classification results are shown in Figure (11).

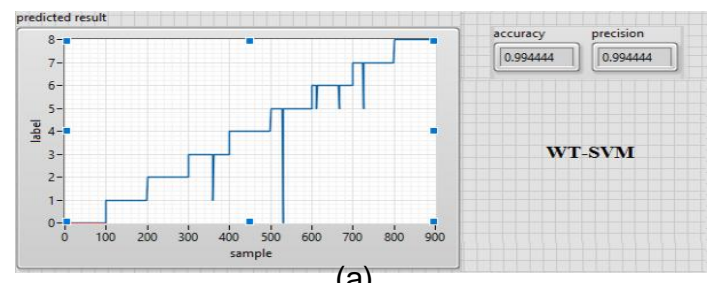

(a)

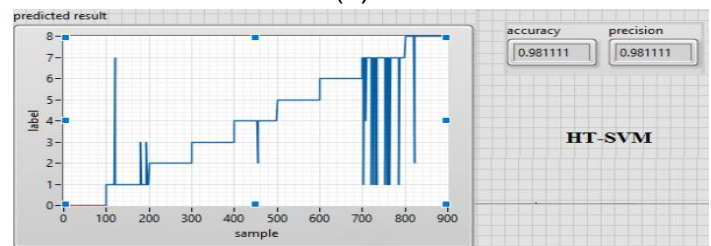

(b)

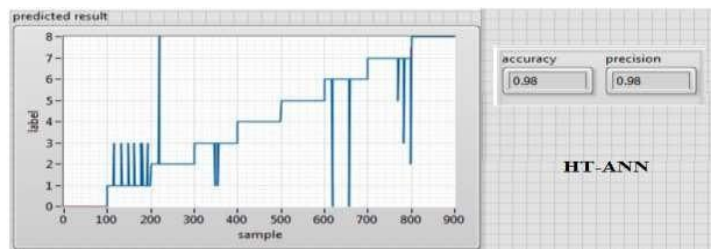

(c)

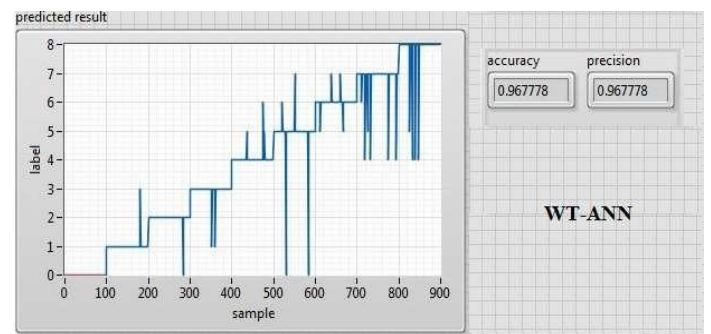

(d)

Fig. 11 Testing results of the four proposed methods (a) WT-SVM, (b) HT-SVM, (c) HT-ANN, (d) WT-ANN 
The following tables illustrate the results including the number of correct classified and misclassified events and the accuracy.

First, DWT- SVM which has the highest value of precision over all the used methods.

Table 2 Classification results using the proposed WT-SVM classifier

\begin{tabular}{|c|c|c|c|c|}
\hline Signals & $\begin{array}{c}\text { Tested } \\
\text { Samples }\end{array}$ & $\begin{array}{c}\text { Correctly } \\
\text { identified }\end{array}$ & $\begin{array}{c}\text { Fault } \\
\text { identified }\end{array}$ & $\begin{array}{c}\text { Precision } \\
(\%)\end{array}$ \\
\hline Pure Sine & 100 & 100 & 0 & 100 \\
\hline Sag & 100 & 100 & 0 & 100 \\
\hline Swell & 100 & 100 & 0 & 100 \\
\hline Transients & 100 & 99 & 1 & 99 \\
\hline Interruptions & 100 & 99 & 1 & 99 \\
\hline Harmonics & 100 & 100 & 0 & 100 \\
\hline Flicker & 100 & 98 & 2 & 98 \\
\hline $\begin{array}{c}\text { Sag \& } \\
\text { Harmonics }\end{array}$ & 100 & 99 & 1 & 99 \\
\hline $\begin{array}{c}\text { Swell \& } \\
\text { Harmonics }\end{array}$ & 100 & 100 & 0 & 100 \\
\hline \begin{aligned} Total \\
\hline\end{aligned} & 9000 & 895 & 5 & 99.44 \\
\hline
\end{tabular}

Second, HT-SVM also has acceptable results.

Table 3 Classification results using the proposed HT-SVM classifier

\begin{tabular}{|c|c|c|c|c|}
\hline Signals & $\begin{array}{c}\text { Tested } \\
\text { Samples }\end{array}$ & $\begin{array}{c}\text { Correctly } \\
\text { identified }\end{array}$ & $\begin{array}{c}\text { Fault } \\
\text { identified }\end{array}$ & $\begin{array}{c}\text { Precision } \\
(\%)\end{array}$ \\
\hline Pure Sine & 100 & 100 & 0 & 100 \\
\hline Sag & 100 & 97 & 3 & 97 \\
\hline Swell & 100 & 100 & 0 & 100 \\
\hline Transients & 100 & 100 & 0 & 100 \\
\hline Interruptions & 100 & 100 & 0 & 100 \\
\hline Harmonics & 100 & 99 & 1 & 99 \\
\hline Flicker & 100 & 100 & 0 & 100 \\
\hline $\begin{array}{c}\text { Sag \& } \\
\text { Harmonics }\end{array}$ & 100 & 88 & 12 & 88 \\
\hline $\begin{array}{c}\text { Swell \& } \\
\text { Harmonics }\end{array}$ & 100 & 99 & 1 & 99 \\
\hline Total & $\mathbf{9 0 0 0}$ & $\mathbf{8 8 3}$ & $\mathbf{1 7}$ & $\mathbf{9 8 . 1 1}$ \\
\hline
\end{tabular}

Third, HT-ANN almost has as the previous method.

Table 4 Classification results using the proposed HT-ANN classifier

\begin{tabular}{|c|c|c|c|c|}
\hline Signals & $\begin{array}{c}\text { Tested } \\
\text { Samples }\end{array}$ & $\begin{array}{c}\text { Correctly } \\
\text { identified }\end{array}$ & $\begin{array}{c}\text { Fault } \\
\text { identified }\end{array}$ & $\begin{array}{c}\text { Precision } \\
(\%)\end{array}$ \\
\hline Pure Sine & 100 & 100 & 0 & 100 \\
\hline Sag & 100 & 90 & 10 & 90 \\
\hline Swell & 100 & 99 & 1 & 99 \\
\hline Transients & 100 & 100 & 0 & 100 \\
\hline Interruptions & 100 & 98 & 2 & 98 \\
\hline Harmonics & 100 & 100 & 0 & 100 \\
\hline Flicker & 100 & 98 & 2 & 98 \\
\hline $\begin{array}{c}\text { Sag \& } \\
\text { Harmonics }\end{array}$ & 100 & 97 & 3 & 97 \\
\hline $\begin{array}{c}\text { Swell \& } \\
\text { Harmonics }\end{array}$ & 100 & 100 & 100 & 100 \\
\hline Total & $\mathbf{9 0 0}$ & $\mathbf{8 8 2}$ & $\mathbf{1 8}$ & $\mathbf{9 8 . 0 0}$ \\
\hline
\end{tabular}

Finally, DWT-ANN which has the lowest value of precision between the used methods.

Table 5 Classification results using the proposed WT-ANN classifier

\begin{tabular}{|l|l|l|l|l|}
\hline Signals & $\begin{array}{l}\text { Tested } \\
\text { Samples }\end{array}$ & $\begin{array}{l}\text { Correctly } \\
\text { identified }\end{array}$ & $\begin{array}{l}\text { Fault } \\
\text { identified }\end{array}$ & $\begin{array}{l}\text { Precision } \\
(\%)\end{array}$ \\
\hline Pure Sine & 100 & 100 & 100 & 100 \\
\hline Sag & 100 & 99 & 1 & 99 \\
\hline Swell & 100 & 99 & 1 & 99 \\
\hline Transients & 100 & 95 & 5 & 95 \\
\hline Interruptions & 100 & 98 & 2 & 98 \\
\hline \begin{tabular}{l} 
Harmonics \\
\hline Flicker
\end{tabular} & 100 & 97 & 3 & 97 \\
\hline $\begin{array}{l}\text { Sag } \\
\text { Harmonics }\end{array}$ & 100 & 96 & 4 & 96 \\
\hline $\begin{array}{l}\text { Swell } \\
\text { Harmonics }\end{array}$ & 100 & 96 & 9 & 91 \\
\hline Total & 9000 & 871 & 29 & 96.78 \\
\hline
\end{tabular}

Table (6) compares the accuracy of the four proposed methods.

Table 6 Accuracy results of all simulated methods

\begin{tabular}{|c|c|c|c|c|}
\hline Method & $\begin{array}{c}\text { DWT- } \\
\text { SVM }\end{array}$ & $\begin{array}{c}\text { HT- } \\
\text { SVM }\end{array}$ & $\begin{array}{c}\text { HT- } \\
\text { ANN }\end{array}$ & $\begin{array}{c}\text { DWT- } \\
\text { ANN }\end{array}$ \\
\hline $\begin{array}{c}\text { Accuracy } \\
(\%)\end{array}$ & 99.44 & 98.11 & 98.00 & 96.78 \\
\hline
\end{tabular}

\section{Discussion}

- All the proposed classification methods give good accuracy results that are between $96.7 \%$ and $99.4 \%$.

- These results show the effectiveness of the features chosen for both DWT and HT.

- The features extracted from DWT are more suitable for SVM classifier whereas the features extracted from HT are more suitable for ANN.

- The lowest accuracy was resulted in DWT-ANN, and this indicates that the DWT features utilized are not much suitable for the ANN classifier.

- ANN classifier had low accuracy in classifying Sag \& Harmonic events with DWT (91\%).

- SVM classifier had low accuracy in classifying Sag \& Harmonic events with HT (88\%).

- SVM classifier proves its robustness and efficiency over ANN.

- The method DWT-SVM expresses a very high accuracy that makes it to be the best one over the other methods, which proves the effectiveness of DWT features for SVM classifier. 


\section{Overall $P Q$ monitoring system}

From the previous results of detection and classification, a proposed method for a power quality monitoring system was deduced. The method utilizes the combination between DWT and SVM; DWT is used for detection and features extraction of disturbances, and SVM classifier is used for identifying the type of disturbances. The system had been successfully simulated and the resulted front panels for the nine events are shown in Figure (12).

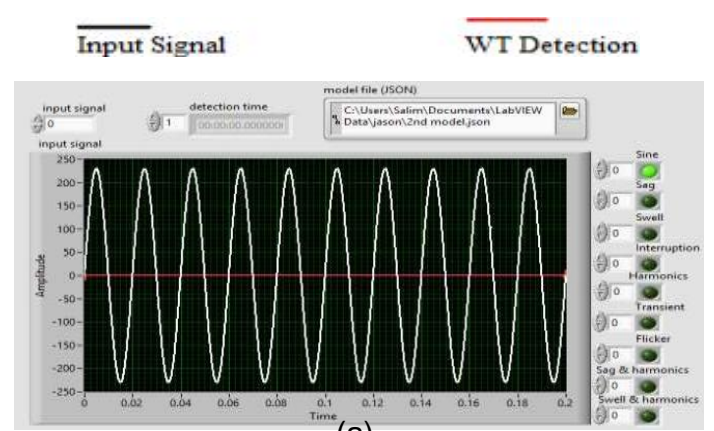

(a)

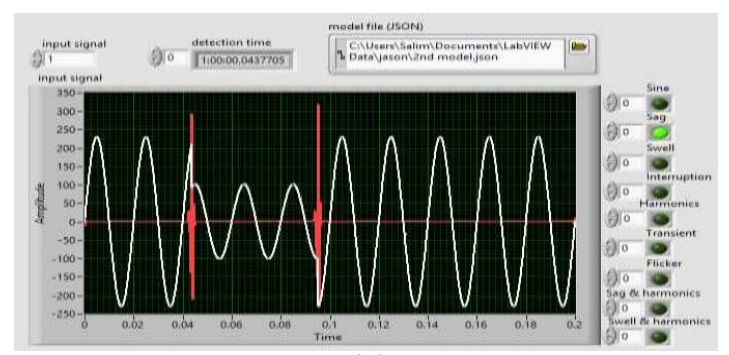

(b)

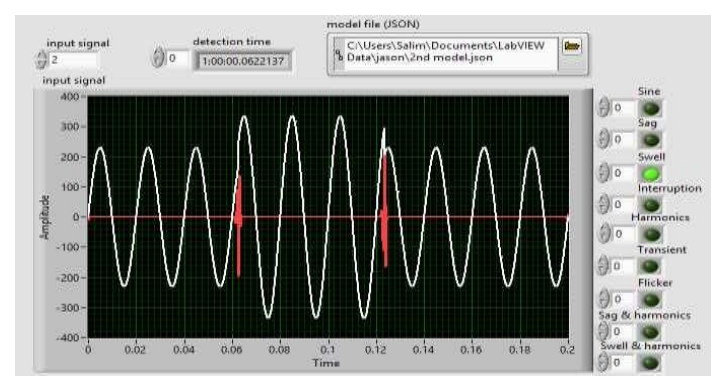

(c)

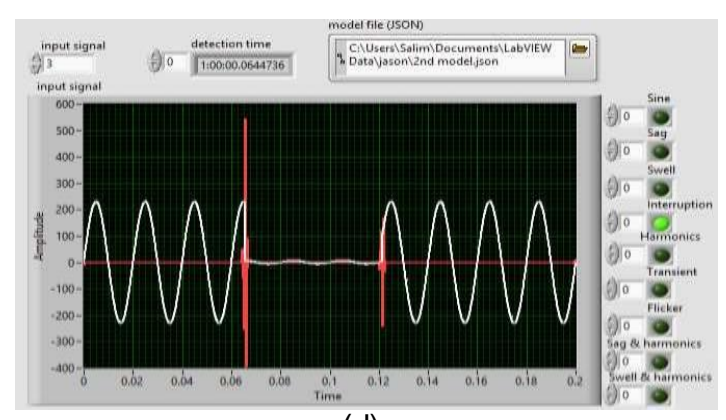

(d)

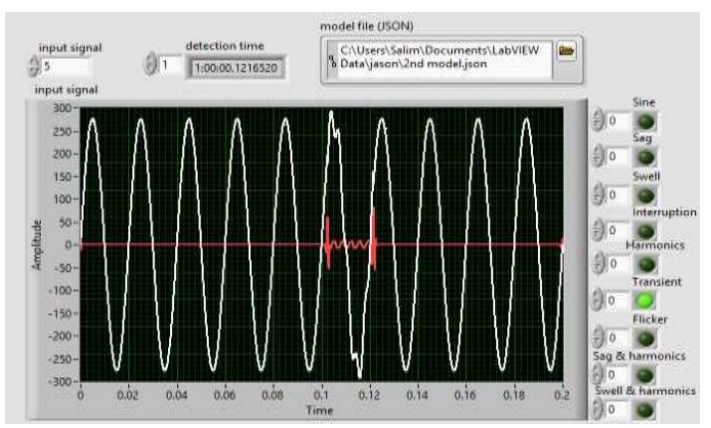

(e)
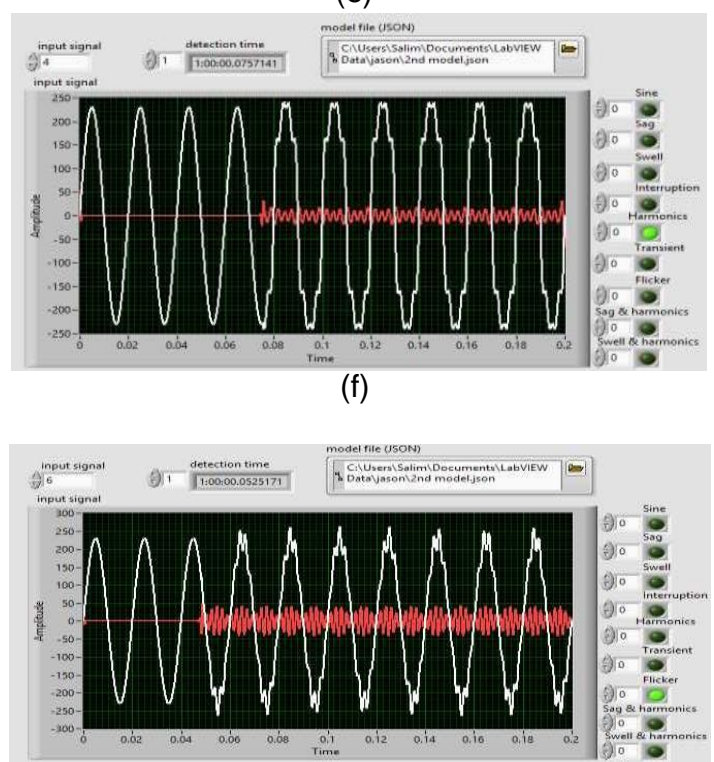

(g)

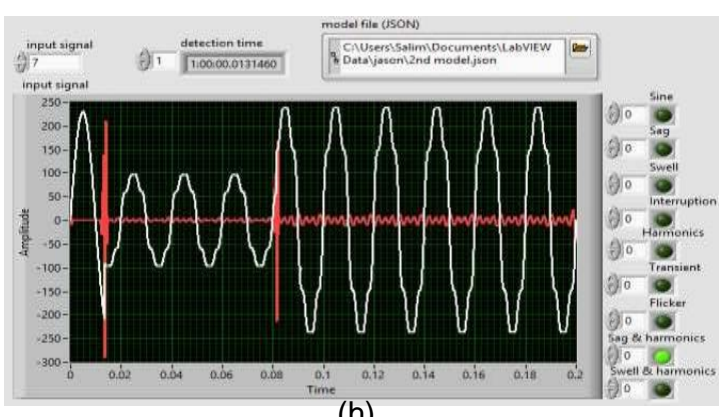

(h)

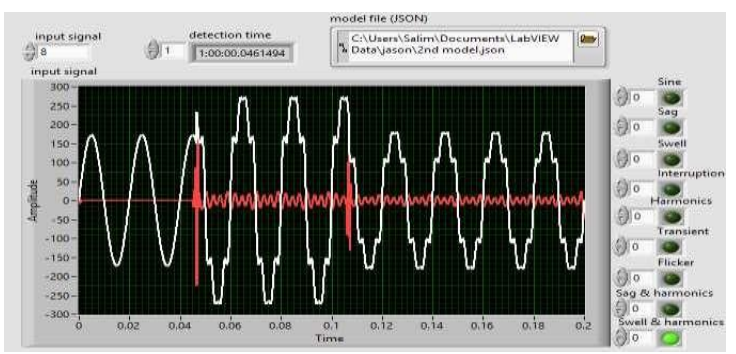

(i)

Fig. 12 PQM Front Panel (a) Sine, (b) Sag, (c) Swell, (d) Interruption, (e) Transients, (f) Harmonics,(g) Flicker, (h) Sag \& Harmonics, (i) Swell \& Harmonics. 


\section{CONCLUSION}

The objectives of this paper were to develop a Power Quality Monitoring system that had the ability to detect power quality disturbances at the minimum possible of time and to correctly identify them with high precision, which is the major area of research in power system field. Wavelet and Hilbert Transforms were introduced as signal processing tools used for detecting and characterizing the Power Quality Disturbances. The two tools have proved their efficiency and flexibility in detecting different disturbances, either the amplitude variation disturbances or the frequency variation ones. Also the machine learning tools ANN and SVM were proposed in the literature to classify the different PQDs, as a result, the accuracy of the classifiers was encouraging by more than $96 \%$ that shows their effectiveness.

\section{Acknowledgments}

This work is part of the research activities within the Laboratory of Signals and Systems, university of Boumerdes, Algeria. Special thanks to Professor Hamid BENTARZI, the director of the signals and systems Laboratory at the University of Boumerdes-Algeria for his valuable advice and continual support.

\section{REFERENCES}

[1] F. Z. Dekhandji, "Signal processing deployment in power quality disturbance detection and classification", ACTA PHYSICA POLONICA A, Vol. 132, No3, PP: 415-419; October 2017.

[2] McGranaghan MF, BeatyHw, Santos S. Dugan RC, Electrical power systems quality, 2nd ed., 1996.

[3] Masoum MA. Fuchs E, Power quality in power systems and electrical machines.: Academic press, 2011 Aug29.

[4] Sankaran C., Power quality.: CRC press, 2001 Dec21

[5] Kennedy BW., Power quality primer.: McGraw Hill Professional, 2000 Oct17.

[6] F. Z. Dekhandji, Detection and mitigation of power quality problems based on phasor measurement units and renewable energy systems, International journal of computational and experimental science and engineering, Vol. 2, № 2, 2016. PP: 10-13.

[7] Baggini A, Handbook of power quality.: John Wiley \& Sons, 2008 Jul31.

[8] Blume D, Stephanblome T Schlabbach J, Voltage quality in electrical power systems.: IET, 2001.

[9] Sarma DS Venkatesh C, Techniques used for
Detection of Power Quality Events-a Comparative Study, 2010 Dec, In16th National Power SystemsConference.

[10] Ram GT, Laxmi AJ Sushama M, "Detection of power quality disturbances using wavelet transforms," International Journal of the Computer, the Internet and Management, vol. 18, no. 1, 2010.

[11] Bansal R, Manana M Zobaa AF, Power quality: Monitoring, analysis and enhancement:BoD-Books on Demand, 2011 Sep22.

[12] Bollen MH, Watson NR Arrillaga JO, "Power quality following deregulation," Proceeding of the IEEE, vol. 88, no. 2, 2000 Feb, Proceeding of thelEEE,.

[13] Bicker R Jabar AA, A Simulation of Nonstationary Signal Analysis Using Wavelet Transform Based on LabVIEW and Matlab, 2014 Oct 21, In 2014 European Modelling Symposium, (pp. 138-144)IEEE.

[14] Abdoos AA, Pazoki M Moravej Z, "Detection and classification of power quality disturbances using wavelet transform and support vector machines," Electric Power Components and Systems, vol. 38, no. 2, 2009 Dec31.

[15] Addison PS, The illustrated wavelet transform handbook: introductory theory and applications in science, 2017 Jan 6, engineering medicine and finance; CRC press.

[16] Abbod M, Alamri B Alshahrani S, Detection and classification of power quality events based on wavelet transform and artificial neural networks for smart grids, 2015 Dec7, In 2015 Saudi Arabia Smart Grid (SASG), (pp. 1-6).

[17] Aggarwal R Kim CH, "Wavelet transforms in power systems, Part 1: General introductionto the wavelet transforms," Power Engineering Journal, vol. 14, no. 2, 2000 Apr1.

[18] Cui Y, Li A Liu Z, "A classification method for complex power quality disturbances using EEMD and rank wavelet SVM," IEEE Transations on Smart Grid, vol. 6, no. 4, pp. (pp. 1678-85), 2015Jul.

[19] Zin AM, Mokhtar AS, Ismail NM, Zaren N Khokhar S, "Automatic classification of power quality disturbances: A review," in In2013 IEEE Student Conference Research and Developemen, IEEE, 2013 Dec 16, pp. (pp.427-432).

[20] Romero-Troncoso RJ, Osornio-Rios RA, Garcia-Perez A, Cabal-Yepez E GranadosLieberman D, "Techniques and methodologies for power quality analysis and disturbances classification in power systems: a review," IET Generation Transmission \&Distribution, vol. 5, no. 4, 2011 Apr 1.

[21] Fausett L. V., Fundamentals of neural networks: architectures, algorithms, and applications. Englewood Cliffs: Prentice-Hall, 1994 Jul1 
[22] K. Warwick, A. Ekwue and R. Aggarwal. "Artificial Intelligence Techniques in Power Systems. (ed). The Institution of Electrical Engineers, London. 1997

[23] Rao KU, Jade S Sridhar S, "Detection and classification of power quality disturbances inthe supply to induction motor using wavelet transform and neural networks," Balkan Journal of Electrical and Computer Engineering, vol. 4, no. 1,2016.

[24] Mishra S, Salama MA, Liew AC Dash PK, "Classification of power system disturbances using a fuzzy expert system and a Fourier linear combiner," IEEE Transactions on power Delivery, vol. 15, no. 2, Apr. 2000.

[25] Lam HK, "Computationa intelligence and its applications: evolutionary comutaion,fuzzy logic, neural network and support vector machine techniques," in World Scientific,2012.

[26] Vapnic V, "The support vector method of function estimation," in InNonlinear Modeling, Springer, Boston, MA, 1998, pp. (pp. 55-85).

[27] Taskovski D Markovska M, "The effectiveness of wavelet based features on power quality disturbances classification in noisy environment," in 2018 18th International Conference on Harmonics and Quality of Power (ICHQP), IEEE, 2018 May 13, pp.(pp.1-6).

[28] Wu CH, Lin CH, Cheng FS Lin WM, "Detection and classification of multiple power- quality disturbances with wavelet multiclass SVM," IEEE transactions on power delivery, vol. 23, no. 4, pp. (pp. 2575-82), Oct. 2008.

[29] Ucar A, Demir Y Eristi H, "Wevelet-based feature extraction and selection for classification of power system disturbances using support vector machines," Electric power systems research, vol. 80, no. 7, 2010. Pp:743-752.

[30] Chandra P., Pahuja P., "Power Quality Monitoring Using LabView," International Journal Of Electrical Electronics \& Computer Engineering, vol. 4, no. 2, pp: 59-65, 2015. 